\title{
O Arquétipo da Filosofia Ambientalista às Margens do Lago Walden
}

\author{
Miguel Ângelo Portela Pinheiro
}

Thoreau, H.D. Walden or Life in the Woods. University Park, PA: Pennsylvania State University, 2006. 261 p.

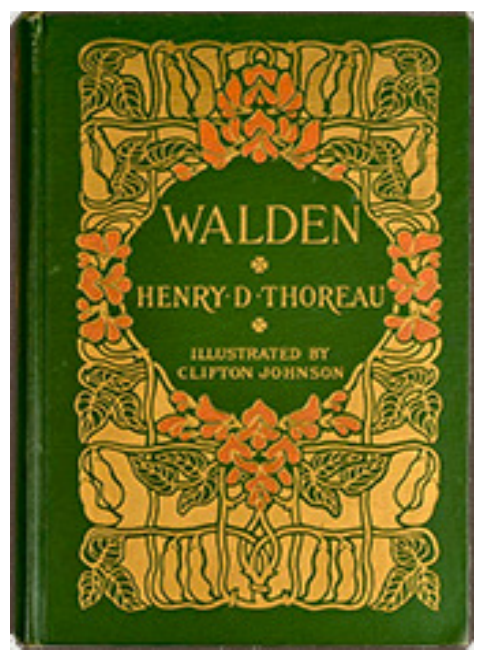

Esta resenha baseia-se no autor estadunidense Henry David Thoreau e seu livro mais famoso, "Walden or Life in the Woods"." Thoreau foi um filósofo ambientalista nos Estados Unidos do século XIX e influenciou vários autores ${ }^{2}$ que sobrevieram a publicação de seus principais trabalhos; "Walden" e "Desobediência Civil"." O primeiro, que será analisado nesta exposição, é um relatos sobre uma experiência bem sucedida do autor, que viveu na natureza "selvagem" e "intocada"4 por mais de dois anos. Thoreau contribuiu significativamente

para o estabelecimento do ambientalismo e diversos conceitos inerentes ao tema, especialmente a noção de educação ambiental.

No ano de 1854, em uma sociedade capitalista que avançava a passos largos para se tornar a maior potência do planeta, o autor era um ferrenho crítico do desenvolvimento e suas imposições. Ele entendia que as pessoas estavam presas em uma típica realidade cotidiana liberal, onde somente dinheiro e posses dignificavam o homem e, por isso, este vivia para trabalhar e se tornava um escravo desta conjuntura social. Em contrapartida, Thoreau advogava que a riqueza de um homem deve ser medida pela quantidade de coisas das quais ele consegue abrir mão.

O filósofo questionava muitas das convenções da cultura central ocidental, desde vestimentas até o estilo de moradia, pois acreditava que estas são medidas restritivas da liberdade individual de cada um. Como o próprio autor coloca ${ }^{5}$, "grande parte do que os meus vizinhos chamam de bom, eu acredito que seja ruim"6 (p. 11). No que concerne aos costumes teoricamente impostos pela sociedade pós-moderna, Thoreau ataca ferozmente o consumismo e o materialismo, forças motrizes da lógica mercantil. Segundo o autor, maior parte dos luxos e confortos da vida não são somente dispensáveis, como também são entraves para a elevação da humanidade. Thoreau era um grande admirador das culturas grega e oriental e rejeitava a luxúria afirmando que os grandes sábios, como os filósofos 
gregos e orientais, sempre viveram de maneira simples, pois eram pessoas de pobreza mundana e riqueza interior.

O autor também cita a padronização de comportamentos como algo a ser denegado, pois seria um fenômeno de caráter egocêntrico, no qual o indivíduo não se contenta apenas com o que lhe convém, mas sim com o que o seu concidadão tem, especialmente se o que este possuir for melhor em alguma espécie de padrão previamente definido. Como exemplo em relação a modismos, Thoreau exemplifica a França, um país tido como referência em estabelecer modelos comportamentais, e ironiza dizendo que "o macaco chefe em Paris põe uma capa de viajar, e todos os macacos na América fazem o mesmo"7 (p. 22).

$\mathrm{Na}$ sua refutação da luxúria e do consumo conspícuo, o filósofo idealiza outras comunidades e culturas, como os índios que foram basicamente rechaçados do território norte-americano. Thoreau compara a questão da moradia nas sociedades "selvagem" e "civilizada". Enquanto na primeira, toda família tem direito a uma oca igual às dos outros, suficientes para suas necessidades básicas, na segunda, uma parcela muito pequena da população possui, de fato, o local onde vive.

[...] [Enquanto] os pássaros do ar têm seus ninhos, e as raposas, as suas tocas, e os selvagens [sic] as suas ocas, [...] nas grandes cidades [...], aqueles que possuem um abrigo são uma parcela muito pequena do todo. $O$ resto paga uma taxa anual [...] que compraria uma aldeia de ocas indígenas, mas agora ajuda a mantê-los pobres enquanto viverem ${ }^{8}$ (p. 26).

O autor questiona: "o selvagem teria sido sábio em trocar sua oca por um palácio sob esses termos?"9 (p. 27). Ele termina sua comparação afirmando que quando o indivíduo finalmente possuir de fato a sua casa, ele estará mais perto de ser pobre do que rico e as relações de domínio terão sido invertidas, pois no final das contas, será a casa que vai possuí-lo.

Frustrado com toda essa realidade, o filósofo se refugiou na natureza e construiu uma cabana em uma floresta na cidade de Concord, nos Estados Unidos, às margens do Lago Walden, onde viveu por dois anos e dois meses. Thoreau tinha como principais objetivos nesta empreitada; refugiarse do sistema que tanto criticava e, simultaneamente, comprovar que era possível viver fora dos limites instituídos pelo mesmo.

Eu fui para a floresta porque eu desejava viver deliberadamente para encarar somente os fatos essenciais da vida e ver se eu poderia aprender o que ela tinha para ensinar, e não quando viesse a morrer, descobrir que não vivi. Eu não desejava viver o que não era vida, viver é tão caro; nem desejava praticar a resignação, a não ser que fosse realmente necessário10 (p. 73).

Enquanto viveu no que chamou de "wilderness"11, o autor escreveu maior parte de "Walden", a sua obra mais cultuada, homônima do lago que tanto venerava. No intuito de viver somente com o essencial para a vida e 
condenar o supérfluo, Thoreau produzia o próprio alimento através da agricultura e construiu uma pequena cabana com apenas um cômodo onde guardava pouquíssimos pertences, dentre os quais descreveu seus livros como os mais importantes. O autor também pretendia comprovar que era possível viver fora do sistema mercantil de moradias alugadas e alimentação industrializada, tarefa na qual obteve sucesso, comprovado pelos gastos e ganhos que teve durante o período e que estão discriminados no seu livro.

Thoreau sempre foi um amante da natureza, o que o levou a embarcar na jornada que descreve em "Walden". O contato intrínseco com o meio natural ao qual se submeteu tornou o filósofo ainda mais sensível à toda a natureza que o cercava. $\mathrm{O}$ autor discorre em longas passagens sobre os animais do local e seus comportamentos, plantas, processos naturais e diversas experiências que the foram proporcionadas pelas imediações do lago Walden. O relato de Thoreau vai desde descrições fonéticas do canto das corujas à noite até o mecanismo de congelamento do lago em cujas margens viveu. O livro finda por ser uma narração descritiva, recheada de nuances filosóficos e poéticos, de uma experiência em que o autor celebra o estabelecimento de uma ligação transcendental e até espiritual com a natureza.

\begin{abstract}
Meus dias na floresta não eram muito longos; eu geralmente levava minha refeição de pão e manteiga, e lia o jornal no qual estivera dobrado, ao meio dia, sentado entre os galhos do pinheiro verde que eu tinha cortado, e para o meu pão foi transmitido um pouco de sua fragrância, pois minhas mãos estavam cobertas com uma espessa camada de sua resina. Antes de terminar, eu já era mais amigo do que inimigo do pinheiro, embora tenha cortado alguns deles, me tornando mais íntimo dele ${ }^{12}$ (p. 35).
\end{abstract}

Uma das principais características desta obra de Thoreau era a atribuição de características animadas à seres inanimados da natureza, na tentativa de passar ao leitor o senso de intimidade que mantinha com eles, como no trecho a seguir, onde se refere à própria natureza:

[...] Uma velha dama também vive na minha vizinhança, [...] em cujos cheirosos jardins eu adoro caminhar às vezes, colhendo elementos e ouvindo suas fábulas, pois ela tem um gênio de fertilidade inigualável, e sua memória vai mais longe do que a mitologia, e ela pode me dizer a origem de todas as fábulas e de qual fato cada uma foi gerada, pois os incidentes ocorreram quando ela era jovem. Uma corada e sadia velha dama, que encanta em todos os climas e estações, e provavelmente viverá mais que todos os seus filhos $^{13}$ (p. 108-109).

Thoreau também descreve no livro a sua defesa pelos direitos dos animais e apologia ao vegetarianismo. Também buscava difundir nas pessoas o prazer pela leitura, especialmente dos livros clássicos gregos e orientais, onde ele achava que se encontravam as respostas para os inúmeros questionamentos feitos na sociedade "civilizada". A leitura desses 
livros e o papel que isso desempenhou na sua vida e na estadia na floresta têm lugar de destaque em "Walden".

Com o passar dos anos na floresta, o estilo de vida de Thoreau e sua filosofia começaram a levantar questionamentos acerca de como estava vivendo, e ele passou a ser perseguido. Porém seguiu com seus ideais até o fim da vida.

\begin{abstract}
Eu não deveria expor tanto meus assuntos [...] se perguntas bastante pessoais não tivessem sido feitas pelos meus concidadãos em relação ao meu modo de vida, que alguns chamariam de impertinente, embora, para mim, não pareça impertinente, mas, considerando as circunstâncias, muito natural e pertinente ${ }^{14}$ (p. 5).
\end{abstract}

É possível inferir que Thoreau inaugurou o movimento e a filosofia ambientalistas no momento em que contrapôs o sistema capitalista em que vivia à natureza, onde o homem poderia ser verdadeiramente livre. A vivência do autor, ainda no século XIX, deu mostras do potencial transformador que a relação íntima com a natureza pode ter no sujeito. Notabilizando-se também como abolicionista e pacifista, Thoreau chegou a ser preso por não pagar impostos ao governo, o que justificava afirmando que se recusava a financiar a escravidão e a guerra que era travada no momento entre Estados Unidos e México. Esses fatos são descritos no seu livro "Desobediência Civil".

\title{
Notas:
}

${ }^{1}$ Título original em inglês: "Walden", que posteriormente se tornou "Walden or Life in The Woods" e foi traduzido para a língua portuguesa como "Walden ou a Vida nos Bosques".

2 Autores como John Burrows e John Muir, considerado idalizador do movimento preservacionista nos EUA.

3 Título original em inglês: "Civil Desobedience".

4 Termos cunhados por Antonio Carlos Diegues no seu livro "O Mito Moderno da Natureza Intocada", de 1994, e que pretendem descrever uma natureza pura e virgem, não impactada pela ação humana.

5 Como as referências de Thoreau presentes nesta resenha foram retiradas de seus escritos originais, as citações diretas são traduções livres do autor deste trabalho. Por isso, também será apresentado o texto original em notas de fim.

6 "The greater part of what my neighbors call good I believe in my soul to be bad $[\ldots] . "$

7 "The head monkey at Paris puts on a traveller's cap, and all the monkeys in America do the same."

8 "In the savage state every family owns a shelter as good as the best, and sufficient for its coarser and simpler wants; but I think that I speak within bounds when I say that, though the birds of the air have their nests, and the foxes their holes, and the savages their wigwams, in modern civilized society not more than one half the families own a shelter. In the large towns and cities, where civilization 
especially prevails, the number of those who own a shelter is a very small fraction of the whole. The rest pay an annual tax for this outside garment of all, become indispensable summer and winter, which would buy a village of Indian wigwams, but now helps to keep them poor as long as they live."

9 "Would the savage have been wise to exchange his wigwam for a palace on these terms?'

10 "I went to the woods because I wished to live deliberately, to front only the essential facts of life, and see if I could not learn what it had to teach, and not, when I came to die, discover that I had not lived. I did not wish to live what was not life, living is so dear; nor did I wish to practise resignation, unless it was quite necessary."

11 THOREAU, 2006, passim. Esta palavra pode ser entendida como a natureza em um estado selvagem.

12 "My days in the woods were not very long ones; yet I usually carried my dinner of bread and butter, and read the newspaper in which it was wrapped, at noon, sitting amid the green pine boughs which I had cut off, and to my bread was imparted some of their fragrance, for my hands were covered with a thick coat of pitch. Before I had done I was more the friend than the foe of the pine tree, though I had cut down some of them, having become better acquainted with it."

13 "An elderly dame, too, dwells in my neighborhood, invisible to most persons, in whose odorous herb garden I love to stroll sometimes, gathering simples and listening to her fables; for she has a genius of unequalled fertility, and her memory runs back farther than mythology, and she can tell me the original of every fable, and on what fact every one is founded, for the incidents occurred when she was young. A ruddy and lusty old dame, who delights in all weathers and seasons, and is likely to outlive all her children yet".

14 "I should not obtrude my affairs so much on the notice of my readers if very particular inquiries had not been made by my townsmen concerning my mode of life, which some would call impertinent, though they do not appear to me at all impertinent, but, considering the circumstances, very natural and pertinent."

Miguel Ângelo Portela Pinheiro: Universidade Federal do Rio de Janeiro, Rio de Janeiro, RJ, Brasil.

E-mail: miguel.ufrrj@gmail.com

Link para o currículo Lattes: http://lattes.cnpq.br/6149955533674498

Data de submissão: 04 de março de 2014

Data de recebimento de correções: 04 de março de 2014

Data do aceite: 11 de maio de 2014

Avaliado anonimamente 